ReseArCH Article

Published May 2, 2020

Correction: This is a corrected version of this article. The original version of this article contained data for an additional ultraviolet light device that has been removed from the corrected version as the device tested is no longer manufactured or supported by the manufacturer. The authors have offered to collaborate with the manufacturer to complete additional testing with a current version of the technology.

\title{
EFFECTIVENESS OF ULTRAVIOLET-C Light and A High-Level Disinfection Cabinet FOR DECONTAMINATION OF N95 RESPIRATORS
}

\section{AUTHORS}

Jennifer L. Cadnum ${ }^{1}$, Daniel F. Li ${ }^{1}$, Sarah N. Redmond², Amrita R. John³ ${ }^{3}$ Basya Pearlmutter ${ }^{1}$, Curtis J. Donskey ${ }^{2,4}$

\section{AFFILIATED INSTITUTIONS}

${ }^{1}$ Research Service; Louis Stokes Cleveland VA Medical Center; Cleveland, Ohio

${ }^{2}$ Geriatric Research, Education, and Clinical Center; Louis Stokes Cleveland VA Medical Center; Cleveland, Ohio

${ }^{3}$ Department of Medicine; University Hospitals Cleveland Medical Center; Cleveland, Ohio ${ }^{4}$ Case Western Reserve University School of Medicine; Cleveland, Ohio

\section{CORRESPONDING AUTHOR}

Curtis J. Donskey

Geriatric Research, Education, and Clinical Center 1110W

Louis Stokes Cleveland VA Medical Center

10701 East Boulevard, Cleveland, Ohio 44106

Phone: 216-791-3800 ext. 64788

Fax: 216-229-8509

\section{SUGGESTED CITATION}

Cadnum JL, Li D, Redmond SN, John AR, Pearlmutter B, Donskey C. Effectiveness of Ultraviolet-C Light and a High-Level Disinfection Cabinet for Decontamination of N95 Respirators. Pathogens and Immunity. 2020;5(1):52-67. doi: 10.20411/pai.v5i1.372

\section{ABSTRACT}

Background: Shortages of personal protective equipment (PPE) including N95 respirators are an urgent concern in the setting of the global COVID-19 pandemic. Decontamination of PPE could be useful to maintain adequate supplies, but there is uncertainty regarding the efficacy of decontamination technologies. 
Methods: A modification of the American Society for Testing and Materials standard quantitative carrier disk test method (ASTM E-2197-11) was used to examine the effectiveness of 3 methods, including ultraviolet-C (UV-C) light, a high-level disinfection cabinet that generates aerosolized peracetic acid and hydrogen peroxide, and dry heat at $70^{\circ} \mathrm{C}$ for 30 minutes. We assessed the decontamination of 3 commercial N95 respirators inoculated with methicillin-resistant Staphylococcus aureus (MRSA) and bacteriophages MS2 and Phi6; the latter is an enveloped RNA virus used as a surrogate for coronaviruses. Three and $6 \log _{10}$ reductions on respirators were considered effective for decontamination and disinfection, respectively.

Results: UV-C administered as a 1-minute cycle in a UV-C box or a 30-minute cycle by a room decontamination device reduced contamination but did not meet criteria for decontamination of the viruses from all sites on the N95s. The high-level disinfection cabinet was effective for decontamination of the N95s and achieved disinfection with an extended 31-minute cycle. Dry heat at $70^{\circ} \mathrm{C}$ for 30 minutes was not effective for decontamination of the bacteriophages.

Conclusions: UV-C could be useful to reduce contamination on N95 respirators. However, the UV-C technologies studied did not meet pre-established criteria for decontamination under the test conditions used. The high-level disinfection cabinet was more effective and met criteria for disinfection with an extended cycle.

Keywords: Ultraviolet-C; decontamination; N95 respirator; peracetic acid; SARS-CoV-2

\section{INTRODUCTION}

Personal protective equipment (PPE) is essential for protection of personnel and patients in healthcare settings [1]. The pandemic of coronavirus disease 2019 (COVID-19) caused by severe acute respiratory syndrome coronavirus 2 (SARS-CoV-2) has resulted in shortages of critical supplies, including PPE [2]. These shortages have led many facilities to consider strategies to extend or reuse PPE, particularly N95 filtering facepiece respirators. The Centers for Disease Control and Prevention and the National Institute for Occupational Safety and Health (NIOSH) have provided guidance on the acceptability of extended use or limited reuse of N95 respirators [3]. The guidance document includes a discussion of potential concerns regarding these practices, particularly the risk for contact transmission from touching a contaminated respirator [ $\underline{3}]$.

Decontamination of N95 respirators and other PPE has been widely discussed as a potential strategy to maintain adequate supplies in crisis situations [4-9]. A variety of decontamination methods have been proposed, including heat and technologies such as ultraviolet-C (UV-C) light and hydrogen peroxide vapor [ $\underline{4}-\underline{9}$ ]. However, there is relatively limited published information on the efficacy of these technologies, and there is uncertainty regarding how to best deploy them (eg, decontamination after each patient interaction or once daily). There is also concern that decontamination technologies could alter the level of protection provided by PPE [ $\underline{10}-\underline{11}]$.

There is an urgent need for evidence regarding the effectiveness of decontamination strategies for PPE. The goal of the current study was to examine the effectiveness of UV-C light and a high-level disinfection cabinet for decontamination of N95 respirators. For UV-C light, we studied a 1-minute cycle delivered by a UV-C decontamination box that could potentially be used for rapid decontamination after each removal of a respirator and a 30-minute treatment delivered by a room decontamination device that might be used once daily. The high-level disinfection 
cabinet generates submicron droplets of aerosolized peracetic acid and hydrogen peroxide and has been shown to be very effective in eliminating microorganisms from hard surfaces in patient rooms and on portable equipment [12-13]. We hypothesized that the disinfection cabinet would be very effective while UV-C light might have reduced efficacy in contrast to previous reports that evaluated microorganism reductions on steel disk carriers or hard surfaces in healthcare settings [14-15]. Soft, irregular surfaces may present a challenge for UV-C decontamination due to the potential for areas of shadowing and absorption of organisms into sites with reduced delivery of UV-C [16].

\section{METHODS}

Table 1 shows the test organisms studied and their characteristics. The enveloped double-stranded RNA virus bacteriophage Phi6 has been used as a surrogate for coronaviruses and influenza in previous studies [17]. The bacteriophages MS2 and Phi6 were propagated as previously described in Escherichia coli and Pseudomonas syringae, respectively [1, 17]. The other test organisms were prepared as previously described [12-13].

Table 1. Characteristics of the test organisms

\begin{tabular}{|c|c|c|}
\hline Organism & Source & Characteristics \\
\hline Acinetobacter baumanii & Clinical isolate & $\begin{array}{l}\text { Non-spore-forming Gram-negative bac- } \\
\text { terium }\end{array}$ \\
\hline $\begin{array}{l}\text { Vancomycin- resistant } \\
\text { Enterococcus faecium }\end{array}$ & Clinical isolate & $\begin{array}{l}\text { VanB type Gram-positive non-spore- } \\
\text { forming bacterium }\end{array}$ \\
\hline $\begin{array}{l}\text { NDM1-producing } \\
\text { Klebsiella pneumoniae }\end{array}$ & ATCC BAA-2146 & $\begin{array}{l}\text { NDM1-producing non-spore-forming } \\
\text { Gram-negative bacterium }\end{array}$ \\
\hline $\begin{array}{l}\text { Methicillin-resistant } \\
\text { Staphylococcus aureus } \\
\text { (MRSA) }\end{array}$ & $\begin{array}{l}\text { Clinical isolate; pulsed- } \\
\text { field gel electrophoresis } \\
\text { type USA } 400\end{array}$ & $\begin{array}{l}\text { Non-spore-forming Gram-positive bacte- } \\
\text { rium }\end{array}$ \\
\hline Escherichia coli & Clinical isolate & $\begin{array}{l}\text { NDM1- producing Non-spore-forming } \\
\text { Gram-negative bacterium }\end{array}$ \\
\hline $\begin{array}{l}\text { Bacteriophage Phi } \\
\text { X174 }\end{array}$ & ATCC 13706-B1 & $\begin{array}{l}\text { Nonenveloped single-stranded DNA virus } \\
(27 \mu \mathrm{m} \text { particle size })\end{array}$ \\
\hline Bacteriophage Phi6 & HER 102 & $\begin{array}{l}\text { Enveloped, double-stranded RNA virus } \\
(85 \mu \mathrm{m} \text { particle size })\end{array}$ \\
\hline Bacteriophage MS2 & ATCC 15597-B1 & $\begin{array}{l}\text { Nonenveloped, single-stranded RNA virus } \\
(26 \mu \mathrm{m} \text { particle size })\end{array}$ \\
\hline Candida auris & $\begin{array}{l}\text { Centers for Disease Con- } \\
\text { trol and Prevention strain } \\
0385\end{array}$ & $\begin{array}{l}\text { Emerging fungal pathogen that is often } \\
\text { resistant to antifungal agents }\end{array}$ \\
\hline Candida albicans & ATCC 10231 & $\begin{array}{l}\text { Yeast that commonly colonizes the gastro- } \\
\text { intestinal tract }\end{array}$ \\
\hline Clostridioides difficile & ATCC 43598 & Spore preparation \\
\hline Bacillus subtilis & ATCC 6051 & Spore-forming Gram-positive bacterium \\
\hline
\end{tabular}

Abbreviations: ATCC, American Type Culture Collection; HER, Félix d'Hérelle Reference Center for bacterial viruses of the Université Laval; NDM, New Delhi metallo-betalactamase. 


\section{Efficacy of UV-C light against the test organisms on steel disk carriers}

Initial testing was performed to assess the efficacy of UV-C against all the test organisms using a modification of the American Society for Testing and Materials standard quantitative carrier disk test method (ASTM E-2197-11) [18]. The purpose of this assessment was to determine the relative susceptibility of bacteriophages Phi6 and MS2 to UV-C in comparison to bacterial and fungal organisms listed in Table 1 . For each pathogen, $10-\mu \mathrm{L}$ aliquots containing $\sim 10^{6}$ colony-forming units (CFU) or plaque-forming units (PFU) in phosphate-buffered saline were spread to cover steel disks $20 \mathrm{~mm}$ in diameter. The steel disk carriers were positioned 32 inches from a room decontamination device (Moonbeam 3, Diversey, Fort Mill, SC) that was operated for a 90-second cycle or 180-second cycle for more UV-C resistant organisms. The relatively short cycle times were chosen in order to allow a comparison in $\log _{10}$ reductions (ie, complete elimination of the inoculum was common for susceptible organisms at higher UV-C doses). The disks were positioned at a height of 3 feet and oriented vertically in parallel with the UV-C bulbs. The disks were processed as previously described [12-13]. $\log _{10}$ CFU or PFU reductions were calculated by comparing recovery from UV-C-exposed carriers to untreated controls.

\section{Efficacy of UV-C light for decontamination of N95 respirators}

For testing of efficacy of UV-C against organisms on N95 respirators, we used the methicillin-resistant Staphylococcus aureus (MRSA) test strain and bacteriophages MS2 and Phi6. Three N95 respirators were studied, the 3M 1860S, Moldex 1517, and Kimberly-Clark 46727. Aliquots of $10 \mu \mathrm{L}$ containing $10^{6} \mathrm{CFU}$ or PFU of the test organisms were suspended in $8 \%$ simulated mucus prepared as previously described [19]. The test organisms were pipetted onto 3 different areas on the respirator surface (outer top, outer edge, and inner surface) (Figure 1). The suspensions were spread with a sterile loop to cover an area of $1 \mathrm{~cm}^{2}$ and allowed to air dry. The respirators were placed inside a UV-C box (Advanced Ultraviolet Systems, South Hill, VA) that provides decontamination with 1 lamp below and 1 above the item to be decontaminated. The UV-C cycle time for the UV-C box was 60 seconds. 

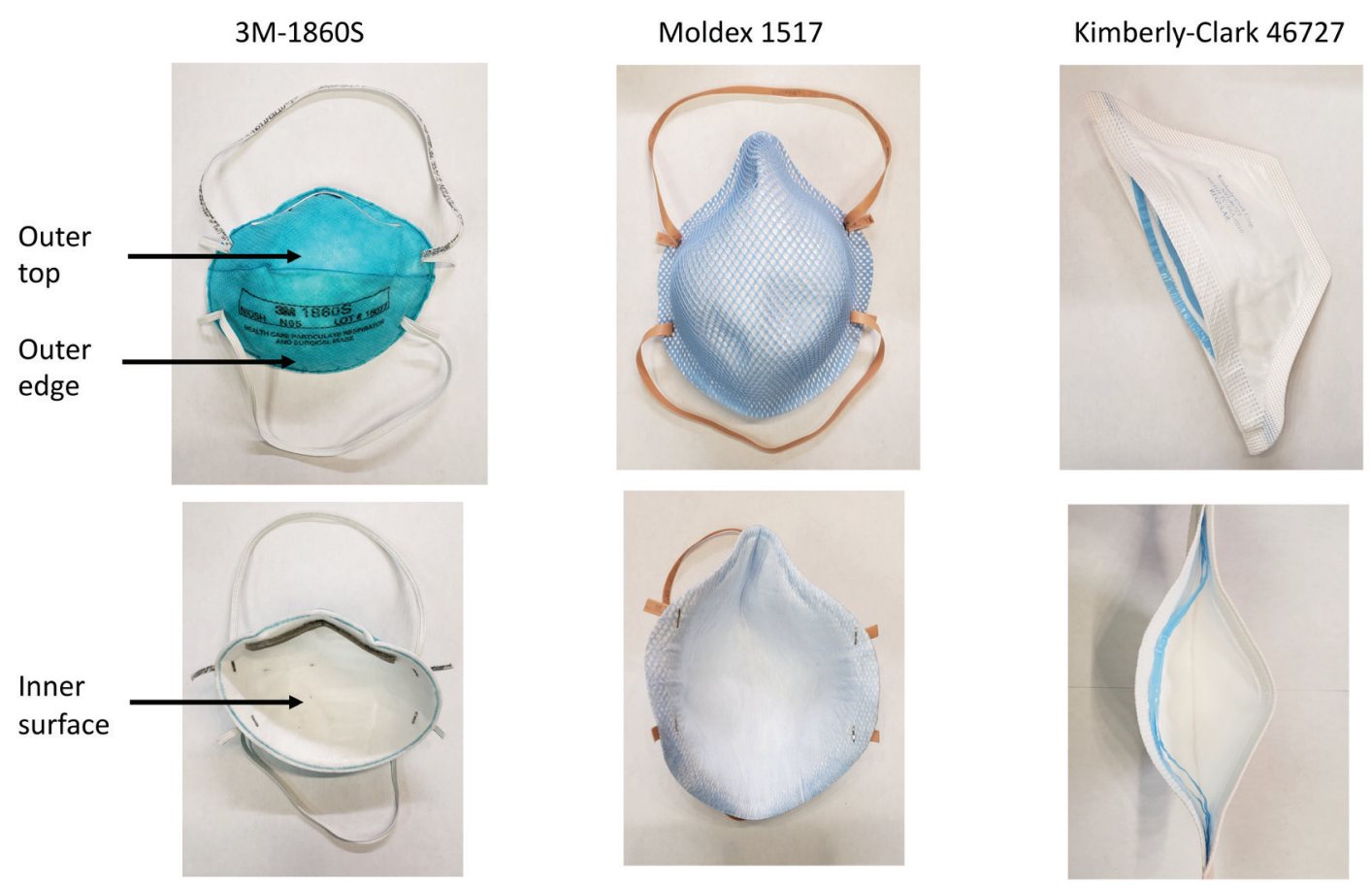

Figure 1. Pictures of the 3 N95 respirators evaluated in the study and areas where the test organisms were applied.

Additional experiments were conducted with the inoculated Moldex 1517 N95 respirator positioned 3 feet from a low-pressure mercury UV room decontamination device (Optimum UV, Clorox Company, Oakland, CA). The device was operated for two cycles; 1 cycle of 15 minutes was performed with the exterior side of the mask facing the lamps and another 15-minute cycle was performed with the interior side of the respirator facing the lamps. For each UV-C experiment, a colorimetric indicator (UVC Dose Indicator, American Ultraviolet, Lebanon, IN) was placed adjacent to the respirator to provide a visual assessment of UV-C delivery to the respirator.

After the UV-C treatments, the inoculated sections of the N95 respirators were cut out, vortexed for 1 minute in $1 \mathrm{~mL}$ of phosphate-buffered saline with $0.02 \%$ Tween, and serial dilutions were plated on selective media to quantify viable organisms. All tests were performed in triplicate. $\log _{10}$ CFU or PFU reductions were calculated by comparing recovery from UV-C-exposed respirators to untreated control respirators.

\section{Efficacy of a multi-purpose high-level disinfection cabinet for decontamination of N95 respirators} The Multi-Purpose High-Level Disinfection Cabinet (Altapure, Mequon, WI) has been described previously [13]. On steel disk carriers, the cabinet was effective in eliminating $\geq 5 \log _{10} \mathrm{PFU}$ or CFU of C. auris, Clostridioides difficile spores, MRSA, and bacteriophage MS2 with a 21-minute total cycle time. This included 1 minute of fogging, 5 minutes of dwell time, and 15 minutes of scrubbing and dehumidification during which peracetic acid, hydrogen peroxide, and acetic acid were removed by passing through activated charcoal filters [13]. The cabinet also was effective in killing Geobacillus stearothermophilus biological indicator spores [1] . 
For testing of efficacy against organisms on an N95 respirator, we used the MRSA test strain and bacteriophage MS2 applied to Moldex 1517 respirators that were inoculated as described previously. We tested 1,2, and 3 cycles of treatment with the cabinet to determine if longer treatment time would increase efficacy. Because multiple cycles increased efficacy, we also tested a single extended cycle with a 15-minute dwell time and 31-minute total cycle time. After completion of the treatment, $\log _{10}$ CFU or PFU reductions were calculated by comparing recovery from exposed respirators to untreated control respirators. The tests were performed in triplicate. For the testing with 3 cycles, additional testing was completed with the 2 other respirator types, and the suspension containing $10^{6} \mathrm{PFU}$ of MS2 and $10^{6} \mathrm{CFU}$ of MRSA was sprayed onto the entire inner and outer surface of the Moldex 1517 respirator. Finally, we tested the efficacy of a single 21-minute cycle against $C$. difficile spores (ATCC strain 43598), MRSA, and bacteriophage MS2.

\section{Efficacy of dry heat for decontamination of N95 respirators}

Heat has been discussed as an alternative to other decontamination methods for SARS-CoV-2. Therefore, we examined the effectiveness of heating $\mathrm{N} 95$ respirators to $70^{\circ} \mathrm{C}$ for 30 minutes in an oven (Economy Incubator, Precision). N95 respirators were contaminated with MRSA and the bacteriophages by pipetting onto 3 different areas of the respirator as previously described, and $\log _{10}$ reductions were calculated.

\section{DATA ANALYSIS}

There is no standard level of germicidal activity recommended for N95 respirators. Rutala et al. [20] have proposed that disinfectants that demonstrate a $3-\log _{10}$ reduction on carriers are likely to be clinically effective on surfaces. For purposes of analysis, we considered a $\geq 3-\log _{10}$ reduction in recovery of organisms inoculated onto N95 respirators to be effective for decontamination of respirators and a $6-\log _{10}$ reduction to be effective for disinfection. Reductions greater than $6 \log _{10}$ were rounded to $6-\log _{10}$ reductions.

Analysis of variance (ANOVA) was performed to compare the mean log10 reductions for the different N95 respirators and for the organisms assessed in dry heat. ANOVA models adjusted for the additional experimental settings (side of mask, organism) while assessing the parameter of interest. All analyses were performed using R version 3.5.1 statistical software (The R Foundation for Statistical Computing, Vienna, Austria).

\section{RESULTS}

\section{Efficacy of UV-C light against the test organisms on steel disk carriers}

Table 2 shows the comparison of $\log _{10}$ CFU or PFU reductions achieved on steel disk carriers by 90 or 180 seconds of exposure to UV-C from a room decontamination device. Bacteriophage MS2 and bacteriophage Phi6 were less susceptible to UV-C than vegetative bacteria such as MRSA, but more susceptible than Candida species and C. difficile spores. 
Table 2. Comparison of $\log 10$ colony-forming unit (CFU) or plaque-forming unit (PFU) reductions achieved on steel disk carriers by 90 seconds or 180 seconds of exposure to UV-C from a room decontamination device.

\begin{tabular}{ll}
\multicolumn{1}{c}{ Time } & \multicolumn{1}{c}{ Organism } \\
(seconds) & \\
90 & Acinetobacter baumanii \\
90 & Vancomycin-resistant Enterococcus faecium \\
90 & Klebsiella pneumoniae \\
90 & MRSA \\
90 & NDM1 Escherichia coli \\
90 & PHI X174 (SS-DNA non-enveloped) \\
90 & PHI 6 (DS-RNA Enveloped) \\
90 & MS2 (SS-RNA non-enveloped) \\
180 & Candida auris \\
180 & Candida albicans \\
180 & Clostridioides difficile spores \\
180 & Bacillus subtillus spores
\end{tabular}

Susceptible to UV-C $\begin{gathered}\log _{10} \\ \text { CFU re- } \\ \text { duction }\end{gathered}$

4.32

3.75

3.69

3.28

3.27

2.49

0.91

0.84

1.13

1.13

1.05

0.72

Resistant to UV-C 


\section{Efficacy of UV-C light for decontamination of N95 respirators}

Figure 2 shows the log reductions achieved on the 3 N95 respirators with the 1-minute cycle in the UV-C box for MRSA, bacteriophage MS2, and bacteriophage Phi6. Reductions in MRSA were consistently greater than reductions of the bacteriophages for most test sites. Reductions in MS2 and Phi6 were similar at most test sites. Differences in reduction across masks were statistically significant $(\mathrm{F}=5.69, \mathrm{df}=2, P<$ 0.01). Reductions were consistently lower on the 3M 1860S N95 respirator in comparison with the other respirators. Reductions were also consistently lower for the interior surfaces of the respirators versus the exterior surfaces; it was noted that the exterior surfaces were impermeable to the liquid suspensions while the interior surfaces were not. For the 3M 1860S N95 respirator, the reductions achieved on the exterior edge were lower than the exterior top surface; for this respirator, the edge has a fold that might result in shadowing that could reduce UV-C delivery (Figure 1).

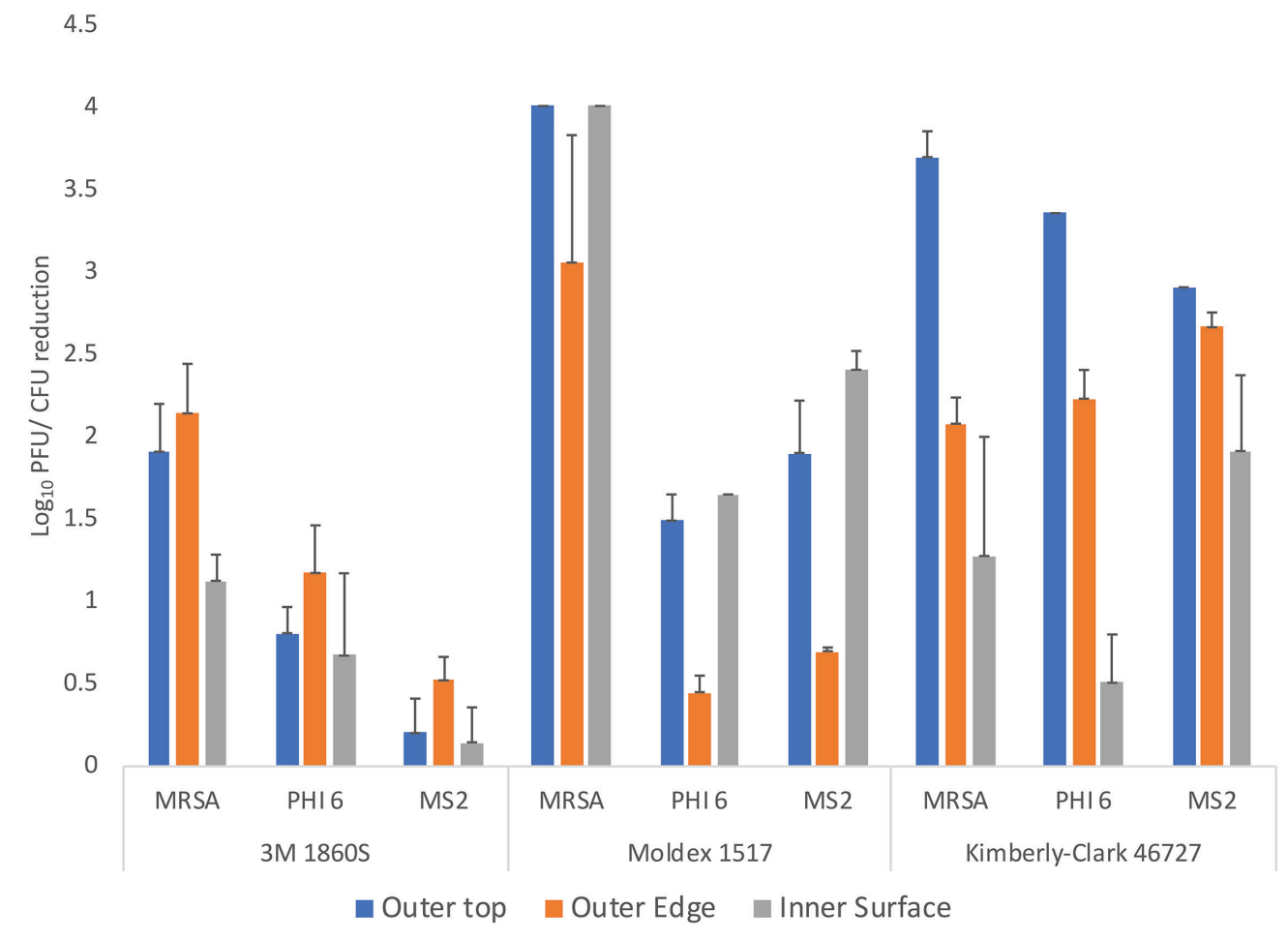

Figure 2. Efficacy of ultraviolet-C (UV-C) light for decontamination of methicillin-resistant Staphylococcus aureus (MRSA), bacteriophage MS2, and bacteriophage Phi6 on 3 different N95 respirators (3M 1860S, Moldex 1517, and Kimberly-Clark 46727). Aliquots of $10 \mu \mathrm{L}$ containing $10^{6}$ colony-forming units (CFU) or plaque-forming units (PFU) of the test organisms in the simulated mucus suspension were spread to cover an area of $1 \mathrm{~cm}^{2}$ on 3 different areas on the respirator surface (top exterior, edge exterior, and interior) as shown in Figure 1. The respirators were exposed to a 60 -second cycle of UV-C inside a UV-C box. Error bars indicate standard error. 
Figure 3 shows the efficacy of UV delivered by the room decontamination device with 2 15-minute cycles for the Moldex 1517 N95 respirator. In general, greater reductions were achieved with the longer UV-C cycles using the low-pressure mercury room decontamination device in comparison to the short cycles in the UV-C box, and reductions on the interior surfaces and the exterior surface were comparable. No visible changes were observed in any of the respirators after 3 or more treatment cycles with the UV-C room decontamination device or with the UV-C box.

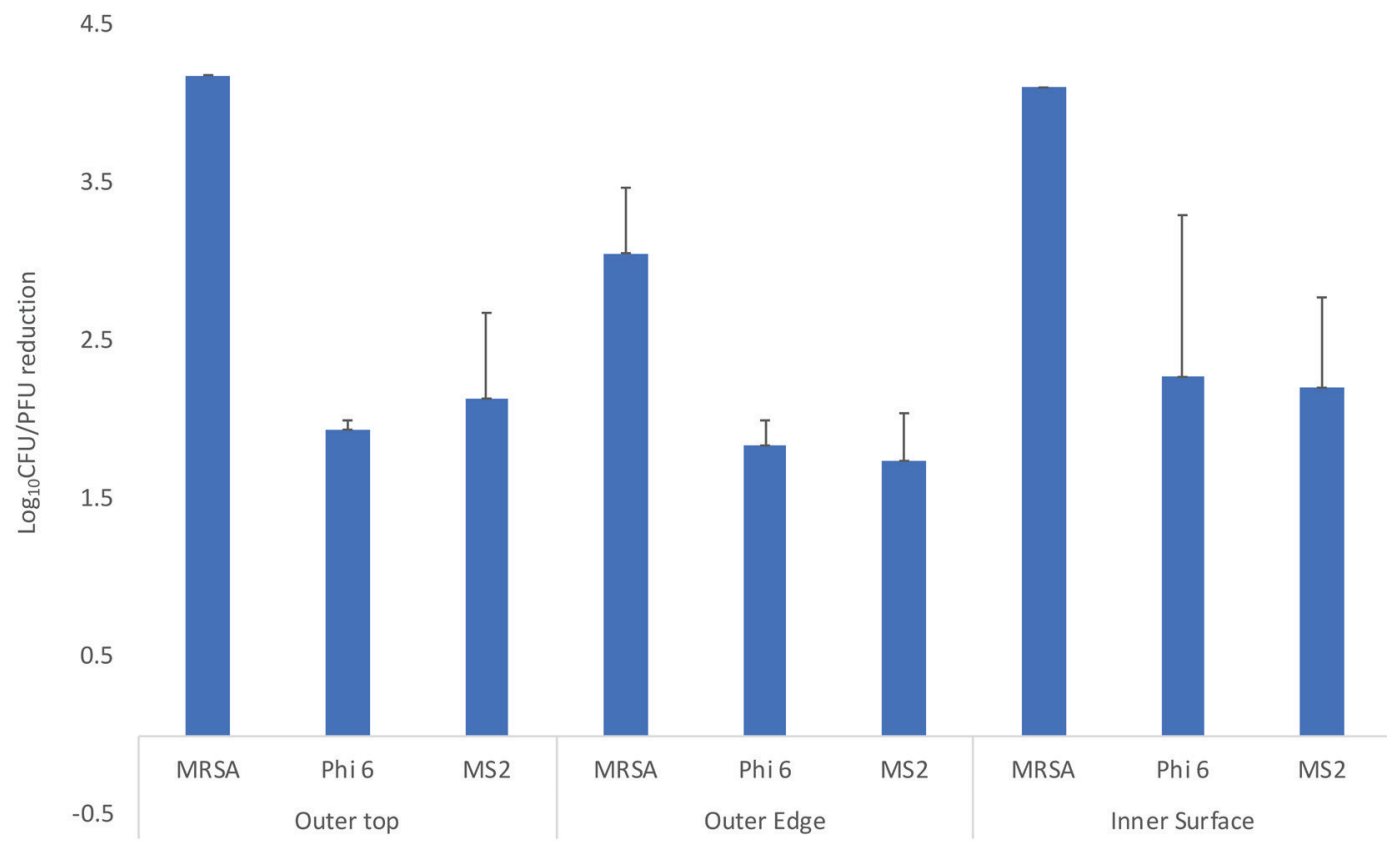

Figure 3. Efficacy of ultraviolet (UV) light delivered by low-pressure mercury decontamination device for decontamination of methicillin-resistant Staphylococcus aureus (MRSA), bacteriophage MS2, and bacteriophage Phi6 on Moldex 1517 N95 respirators. 10- $\mu$ L aliquots containing $10^{6}$ colony-forming units (CFU) or plaque-forming units (PFU) of the test organisms in the simulated mucous suspension were spread to cover an area of $1-\mathrm{cm} 2$ on 3 different areas on the respirator surface (top exterior, edge exterior, and interior) as shown in Figure 1. The respirator was exposed to a 15-minute cycle of UV at 3 feet from the bulbs then turned for another 15-minute cycle on the opposite side. Error bars indicate standard error. 
Figure 4 shows the changes in the UV-C colorimetric indicators with each type of UV-C treatment. In the UV-C box, the respirators are placed on narrow slats that are purported to allow UV-C passage. However, as shown in Figure 4, lines present at the site of the slats demonstrate that UV-C penetration was reduced. Both the 1-minute cycle in the UV-C box and the 30-minute cycle with the low-pressure mercury room decontamination device resulted in a color change from yellow (untreated) to pink, indicating delivery of a dose sufficient to reduce C. difficile spores.
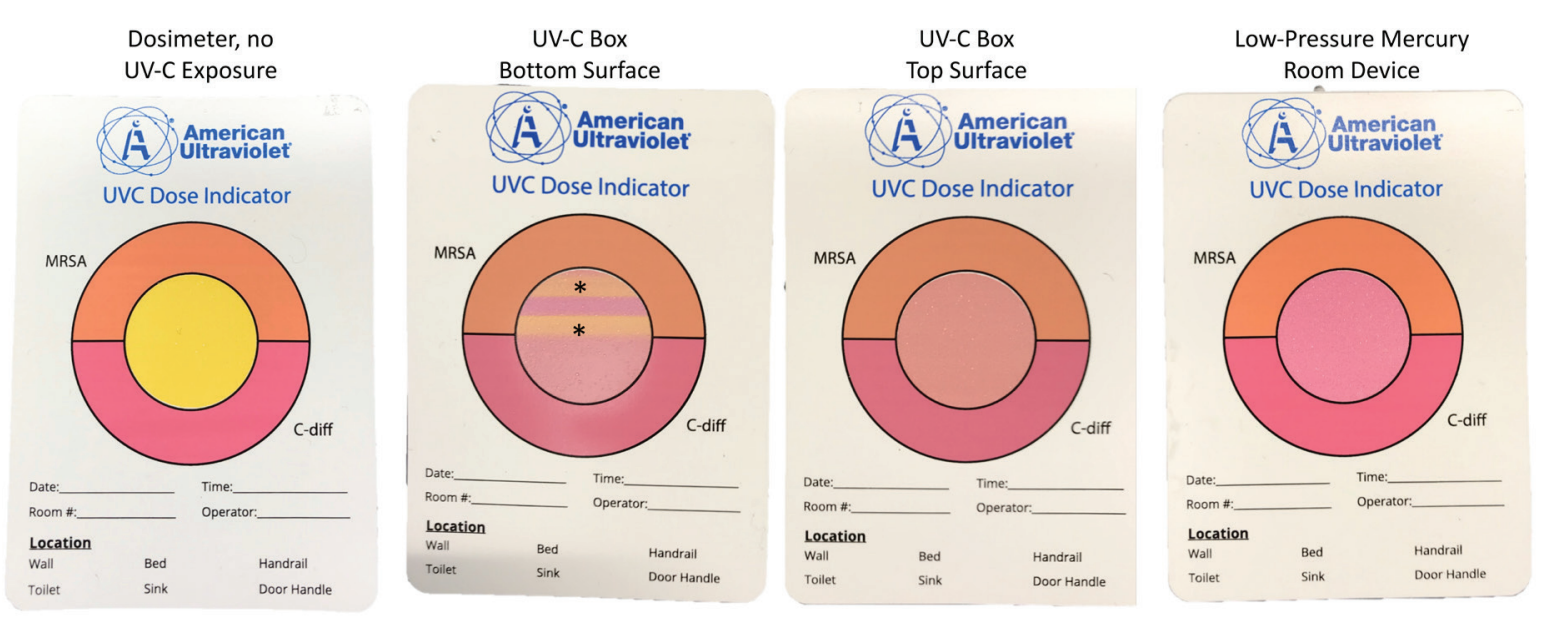

Figure 4. Pictures showing colorimetric indicators placed adjacent to respirators during ultraviolet-C cycles.

\section{Efficacy of a multi-purpose high-level disinfection cabinet for decontamination of N95 respi- rators}

Figure 5 shows the efficacy of a high-level disinfection cabinet for decontamination of Moldex 1517 respirators inoculated with MRSA and bacteriophage MS2. With 1, 2, and 3 treatment cycles of 21 minutes and with an extended 31 -minute cycle, reductions of $\geq 2.1, \geq 3.6$, and $>6 \log _{10}$ PFU or CFU were achieved for all the test sites. Additional testing with the other 2 respirator types demonstrated similar results for the 3 consecutive 21 -minute cycles and for the single extended 31-minute cycle. The 3 -cycle treatment was effective in achieving $>6-\log _{10}$ PFU or CFU reductions on the Moldex 1517 respirator when the suspension containing $10^{6} \mathrm{PFU}$ of MS2 and $10^{6} \mathrm{CFU}$ of MRSA was sprayed onto the entire inner and outer surface of the Moldex 1517 respirator. No visible changes were observed in any of the respirators after 3 or more cycles of decontamination. 


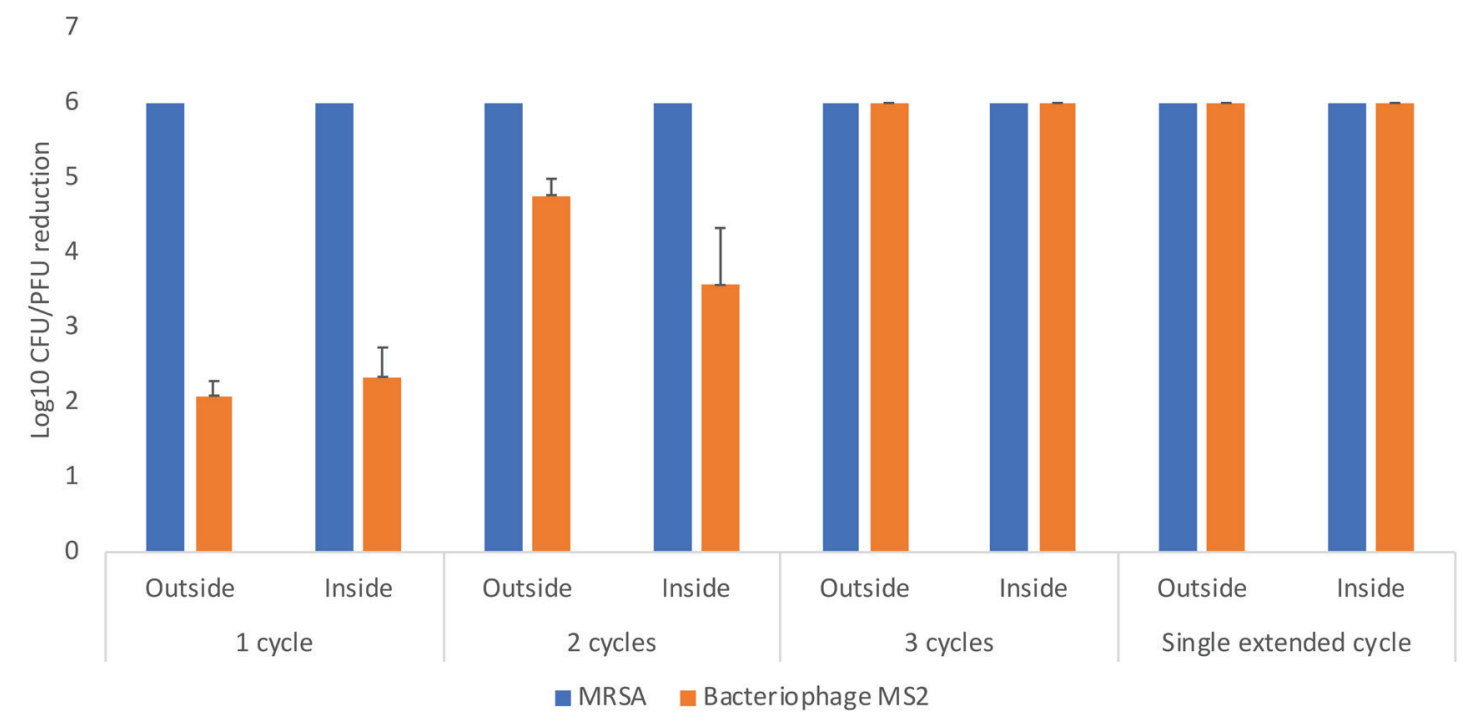

Figure 5. Efficacy of a multi-purpose high-level disinfection cabinet for decontamination or disinfection of methicillin-resistant Staphylococcus aureus (MRSA) and bacteriophage MS2 on N95 respirators. 10- $\mu \mathrm{L}$ aliquots containing $10^{6}$ colony-forming units (CFU) or plaque-forming units (PFU) of the test organisms in the simulated mucous suspension were spread to cover an area of $1-\mathrm{cm}^{2}$ on 3 different areas on the respirator surface (top exterior, edge exterior, and interior) as shown in Figure 1. The respirator was exposed to 1, 2, or 322 -minute treatment cycles or a single extended cycle of 31 minutes. Error bars indicate standard error.

\section{Efficacy of dry heat for decontamination of $\mathrm{N95}$ respirators}

Dry heat at $70^{\circ} \mathrm{C}$ for 30 minutes had limited effectiveness against bacteriophages MS2 and Phi6 versus MRSA $\left(<1 \log _{10}\right.$ PFU versus $>4 \log _{10}$ CFU respectively, $\left.\mathrm{F}=54.7, \mathrm{df}=2, P<0.01\right)$.

\section{DISCUSSION}

Shortages of PPE are a grave concern for many healthcare facilities in the setting of the global COVID-19 pandemic. Our findings have important implications for facilities that are considering decontamination of PPE as a potential strategy to maintain adequate supplies. Using a rigorous test method, we found that UV-C reduced contamination of N95 respirators with Phi6 and MS2 bacteriophages and MRSA. However, there was considerable variability in reductions achieved on different respirator brands and on different locations on the respirators. The efficacy on the interior surface of the respirator was reduced in comparison to the outer surface, possibly due to the permeability of the inner surfaces to the liquid suspensions resulting in reduced access by UV-C.

Our results suggest that facilities might consider use of the UV-C box or room decontamination devices to reduce contamination on respirators that will be reused by individuals. However, the levels of reduction did not meet our pre-established criteria for decontamination (ie, $\geq 3-\log _{10}$ reduction on inoculated respirators), and moreover would not have met a $\geq 2-\log _{10}$ reduction 
requirement for decontamination. Thus, the level of reduction would not be adequate to allow shared use of respirators by different individuals.

The high-level disinfection cabinet was more effective than UV-C and provided 2.1 or greater $\log _{10}$ reductions in bacteriophage MS2 on both outer and inner surfaces of the respirator with a single cycle. It is notable that this level of reduction is substantially lower than the 6- $\log _{10}$ reductions in bacteriophage MS2 achieved on solid carriers in previous studies with this technology [12-13]. Moreover, the single cycle resulted in $>6-\log _{10}$ reductions in MRSA and C. difficile spores inoculated on the respirator, despite greater UV-C resistance of these organisms on solid surfaces. Taken together, these data suggest that reduction in viral pathogens on N95 respirators might be challenging, in part because the small size of viral particles allows them to penetrate beneath the respirator surface to a greater extent than bacteria resulting in partial protection from technologies such as UV-C and aerosolized peracetic acid. These data also highlight the importance of including viruses in the testing of technologies proposed for N95 respirator decontamination.

With 3 consecutive cycles or an extended cycle, the high-level disinfection cabinet met criteria for disinfection, achieving $>6-\log _{10}$ reductions on N95 respirators. The same technology is available as a room decontamination device that would provide additional space for larger quantities of PPE [12]. On solid surfaces, the efficacy of the high-level disinfection cabinet is similar to that reported for hydrogen peroxide vapor, which has also been considered as an option for PPE decontamination $[\underline{9}, \underline{21}]$. Given the efficacy of the disinfection cabinet, this type of technology could potentially be used for disinfection of PPE that would be shared among different individuals in the setting of a crisis with inadequate supplies of PPE.

We found that dry heat in an oven at $70^{\circ} \mathrm{C}$ for 30 minutes had limited effectiveness for decontamination of inoculated respirators. Previous reports suggest that heat can be very effective against viruses in liquid suspension and heated droplets [22-25]. The relative lack of efficacy of heat in our study may be attributable to the use of dry rather than moist heat, inoculation onto respirators rather than hard surfaces or liquid suspensions, and characteristics of the viruses being tested. Lore et al. [4] and Heimbuch et al. [] ] found that moist heat $\left(65^{\circ} \mathrm{C}\right.$ for 20 minutes) was effective for inactivation of influenza virus. Darnell et al. [22] found that heating a liquid suspension with virus particles for 45 minutes at $75^{\circ} \mathrm{C}$ or 90 minutes at $65^{\circ} \mathrm{C}$ was effective for inactivation of SARS-CoV. Further studies are needed that include use of moist and dry heat for reduction of viruses inoculated onto respirators.

Our study has several limitations. First, we did not address the concern that decontamination technologies could alter the level of protection provided by PPE [ $\underline{10}-\underline{11}]$. Further studies are currently being conducted to evaluate the impact of multiple different decontamination methods on N95 performance such as filtration efficiency. Second, we applied the test organisms in a liquid suspension directly onto the surface of the N95 respirators and spread them over a relatively small surface area with a loop. We cannot exclude the possibility that the technologies would have been more effective if the inoculum was spread out over a larger surface area; spreading of an organism inoculum over a larger surface area has been shown to increase the efficacy of UV-C light [14-15]. It has also been suggested that the method of deposition may influence results, and that methods that more closely mimic droplet and aerosol deposition on respirators should be used [] $]$. For the disinfection cabinet, we conducted additional experiments in which the inoculum was applied to 
the entire respirator as a fine spray with similar results (data not shown). Third, the testing was conducted as a laboratory simulation. Additional studies are needed to evaluate decontamination of N95 respirators used in clinical settings. Fourth, UV-C was less effective in our study than has been reported in previous investigations of UV-C for decontamination of influenza virus on respirators $[\underline{4}, \underline{6}]$. This may be related to differences in methodology or to greater UV-C susceptibility of influenza virus than the bacteriophages studied. Previous studies suggest that viruses vary considerably in susceptibility to UV-C [26]. Fifth, we cannot exclude the possibility that a higher UV-C dose might have resulted in greater efficacy. However, there is evidence that very high UV-C doses may adversely affect N95 respirator performance and structural integrity [10]. Sixth, we only studied 3 brands of N95 respirators and 3 methods of decontamination. We are currently evaluating the effectiveness of several other technologies. Finally, we did not include data on decontamination of other types of PPE. However, testing with surgical face masks yielded similar results (data not shown).

In summary, we found that UV-C reduced contamination of N95 respirators with Phi6 and MS2 bacteriophages and MRSA. However, efficacy varied with different respirator types and with different locations on the respirator. A high-level disinfection cabinet using submicron droplets of aerosolized peracetic acid and hydrogen peroxide was substantially more effective for decontamination of N95 respirators and with 3 consecutive cycles or a single extended cycle achieved $>6$ $\log _{10}$ reductions meeting criteria for disinfection. Further work is urgently needed to determine the impact of decontamination technologies on respirator function.

\section{ACKNOWLEDGMENTS}

We would like to thank William Rutala and John Boyce for helpful discussions and critical review of the manuscript.

\section{FINANCIAL SUPPORT}

This work was supported by a Merit Review grant (1 I01 BX002944-01A1) from the Department of Veterans Affairs to C.J.D.

\section{CONFLICTS OF INTEREST}

Curtis J. Donskey has received research grants from Clorox, Merck, Pfizer, and PDI. He also serves as an associate editor for Pathogens and Immunity. All other authors report no conflicts of interest relevant to this article.

\section{REFERENCES}

1. Tomas ME, Kundrapu S, Thota P, Sunkesula VC, Cadnum JL, Mana TS, Jencson A, O’Donnell M, Zabarsky TF, Hecker MT, Ray AJ, Wilson BM, Donskey CJ. Contamination of the skin and clothing of healthcare personnel during removal of personal protective equipment. JAMA Intern Med 2015;175:1904-10. doi: 10.1001/jamainternmed.2015.4535.

2. Ranney ML, Griffeth V, Jha AK. Critical Supply Shortages - The Need for Ventilators and Personal Protective Equipment during the Covid-19 Pandemic. N Engl J Med 2020 Mar 25. doi: 10.1056/NEJMp2006141. 
3. https://www.cdc.gov/niosh/topics/hcwcontrols/recommendedguidanceextuse.html

4. Lore MB, Heimbuch BK, Brown TL, Wander JD, Hinrichs SH. Effectiveness of Three Decontamination Treatments against Influenza Virus Applied to Filtering Facepiece Respirators. Ann Occupat Hyg 2012;56:92-101. https://doi.org/10.1093/annhyg/ mer054

5. Viscusi DJ, Bergman MS, Eimer BC, Shaffer RS. Evaluation of Five Decontamination Methods for Filtering Facepiece Respirators. Ann Occup Hyg 2009;53:815-827. https://doi.org/10.1093/annhyg/mep070

6. Heimbuch BK, Wallace WH, Kinney K, Lumley AE, Wu C, Woo M, Wander JD. A pandemic influenza preparedness study: use of energetic methods to decontaminate filtering facepiece respirators contaminated with $\mathrm{H} 1 \mathrm{~N} 1$ aerosols and droplets. Am J Infect Control 2011;39:e1-e9. doi: 10.1016/j.ajic.2010.07.004.

7. Fisher EM, Shaffer RE. A method to determine the available UV-C dose for the decontamination of filtering facepiece respirators. J Appl Microbiol 2011;110: 287-295. doi: 10.1111/j.1365-2672.2010.04881.x.

8. Lowe JL, Paladino KD, Farke JD, Boulter K, Cawcutt K, Emodi M, Gibbs S, Hankins R, Hinkle L, Micheels T, Schwedhelm S, Vasa A, Wadman M, Watson S, and Rupp ME. N95 Filtering Facemask Respirator Ultraviolet Germicidal Irradiation (UVGI) Process for Decontamination and Reuse. 2020. https://www.nebraskamed.com/for-providers/ covid19

9. Schwartz A, Stiegel M, Greeson N, Vogel A, Thomann W, Brown M, Sempowski GD, Alderman TS, Condreay JP, Burch J, Wolfe C, Smith B, and Lewis S. Decontamination and Reuse of N95 Respirators with Hydrogen Peroxide Vapor to Address Worldwide Personal Protective Equipment Shortages During the SARS-CoV-2 (COVID-19) Pandemic. Applied Biosafety: Journal of ABSA International. 2020. Preprint. https:// absa.org/decontamination-and-reuse-of-n95-respirators-with-hydrogen-peroxide-vapor-to-address-worldwide-personal-protective-equipment-shortages-during-the-sarscov-2-covid-19-pandemicl

10. Lindsley WG, Martin Jr. SB, Thewlis RE, Sarkisian K, Nwoko JO, Mead KR, Noti JD. Effects of Ultraviolet Germicidal Irradiation (UVGI) on N95 Respirator Filtration Performance and Structural Integrity. J Occup Envviron Hyg 2015;12:509-517. DOI: 10.1080/15459624.2015.1018518.

11. 3M Personal Safety Division. Disinfection of Filtering Facepiece Respirators Technical Bulletin. 2020. https://www.3m.com/3M/en_US/worker-health-safety-us/all-stories/ full-story-detail/?storyid=8855304f-01cb-4af2-8937-83096cdb4113

12. Mana TS, Sitzlar B, Cadnum JL, Jencson AL, Koganti S, Donskey CJ. Evaluation of an automated room decontamination device using aerosolized peracetic acid. Am J Infect Control 2017;45:327-329. doi: 10.1016/j.ajic.2016.10.006.

13. Kumar JA, Cadnum JL, Jencson AL, Donskey CJ. Efficacy of a multi-purpose high level disinfection cabinet against Candida auris and other health care-associated pathogens. Am J Infection Control 2019 Dec 23. pii: S0196-6553(19)31016-8. doi: 10.1016/j. ajic.2019.11.029. 
14. Boyce JM, Donskey CJ. Understanding ultraviolet light surface decontamination in hospital rooms: A primer. Infect Control Hosp Epidemiol 2019;40:1030-1035. doi:10.1017/ice.2019.161

15. Donskey CJ. Decontamination devices in health care facilities: Practical issues and emerging applications. Am J Infect Control 2019;47S:A23-A28. doi: 10.1016/j. ajic.2019.03.005.

16. Smolle C, Huss F, Lindblad M, Reischies F, Tano E. Effectiveness of automated ultraviolet-C light for decontamination of textiles inoculated with Enterococcus faecium. Am J Infect Control 2018;98:102-104. doi: 10.1016/j.jhin.2017.07.034.

17. Casanova LM. Evaluation of eluents for the recovery of an enveloped virus from hands by whole-hand sampling. J Appl Microbiol 2015;118:1210-1216. doi:10.1111/ jam.12777.

18. ASTM International, Designation E2197: Standard Quantitative Disk Carrier Test Method for Determining Bactericidal, Virucidal, Fungicidal, Mycobactericidal, and Sporicidal Activities of Chemicals, 2011.

19. Masiuk T, Kadakia P, Wang Z. Development of a Physiologically Relevant Dripping Analytical Method Using Simulated Nasal Mucus for Nasal Spray Formulation Analysis. J Pharmaceut Anal 2016;6:283-291. doi:10.1016/j.jpha.2016.05.003.

20. Rutala WA, Kanamori H, Gergen MF, Sickbert-Bennett EE, Weber DJ. Susceptibility of Candida auris and Candida albicans to 21 germicides used in healthcare facilities. Infect Control Hosp Epidemiol 2019;40:380-382. doi: 10.1017/ice.2019.1.

21. Final Report for the Bioquell Hydrogen Peroxide Vapor (HPV) Decontamination for Reuse of N95 Respirators. In: Threats FOoCaE, ed.: Battelle; 2016.

22. Darnell ME, Subbarao K, Feinstone SM, Taylor DR. Inactivation of the coronavirus that induces severe acute respiratory syndrome, SARS-CoV. J Virol Methods 2004;121:85-91.

23. Firquet S, Beaujard S, Lobert PE, Sane F, Caloone D, Izard D, Hober D. Viruses contained in droplets applied on warmed surface are rapidly inactivated. Microbes Environ. 2014;29(4):408-12. PubMed PMID: PMC4262365. doi: 10.1264/jsme2.ME14108

24. Rabenau HF, Cinatl J, Morgenstern B, Bauer G, Preiser W, Doerr HW. Stability and inactivation of SARS coronavirus. Med Microbiol Immunol 2005;194:1-6. doi:10.1007/ s00430-004-0219-0.

25. Leclercq I, Batéjat C, Burguière AM, Manuguerra JC. Heat inactivation of the Middle East respiratory syndrome coronavirus. Influenza Other Respir Viruses 2014;8:585586. doi:10.1111/irv.12261.

26. Tseng CC, Li CS. Inactivation of viruses on surfaces by ultraviolet germicidal irradiation. J Occup Environ Hyg 2007;4:400-5. 


\section{FOOTNOTES}

Submitted April 3, 2020 | Accepted April 7, 2020 | Published May 2, 2020

\section{COPYRIGHT}

Copyright @ 2020 Pathogens and Immunity.

This is an open-access article distributed under the terms of the Creative Commons Attribution 4.0 International License. 